\title{
TENDÊNCIA METODOLÓGICA DOS ESTUDOS DE REVISÃO EM EDUCAÇÃO NO PERIÓDICO “PROPOSIÇÕES” (2000 - 2016)
}

\author{
Victória Carneiro Sousa ${ }^{1}$; Elizabete Pereira Barbosa ${ }^{2}$ \\ 1. Bolsista PIBIC/CNPq, Graduanda em Licenciatura em História, Universidade Estadual de Feira de Santana, e- \\ mail: victoriacsousa727@gmail.com \\ 2. Orientadora, Departamento de Educação, Universidade Estadual de Feira de Santana, e-mail: beteuefs@ gmail.com
}

PALAVRAS-CHAVE: Estado da arte, Estado do conhecimento, Estudos de revisão.

\section{INTRODUÇÃO}

O presente texto enfoca os resultados do estudo que mapeia e caracteriza as tendências metodológicas dos estudos de revisão na Revista Pro-Posições, no período 2000 a 2016. É parte integrante do projeto de pesquisa "Estudos de Revisão em Educação: tipologias e tendências metodológicas (2000-2016)". Estudos de revisão ou estado da arte são pesquisas cujo objeto de estudo é a produção acadêmica, a fim de caracterizar essa produção, indicar tendências e vacuidades e, portanto, promover novos encaminhamentos que ajudam a avançar e organizar a construção do conhecimento. Como indica Joana Paulin Romanowski:

Estados da arte podem significar uma contribuição importante na constituição do campo teórico de uma área de conhecimento, pois procuram identificar os aportes significativos da construção da teoria e prática pedagógica, apontar as restrições sobre o campo em que se move a pesquisa, as suas lacunas de disseminação, identificar experiências inovadoras investigadas que apontem alternativas de solução para os problemas da prática e reconhecer as contribuições da pesquisa na constituição de propostas na área focalizada. (ROMANOWSKI; ENS, 2006, p. 39).

A pesquisa intitulada Estudos de Revisão em Educação: tipologias e tendências metodológicas (2000-2016) intenta caracterizar os trabalhos que pesquisam a produção acadêmica (estudos de revisão), a partir de um conjunto específico de trabalhos selecionados, a fim de indicar as tendências, as potencialidades e os desafios que se apresentam à área de educação, frente a esse tipo de pesquisa. É necessário entender de que forma esses estudos de revisão estão sendo produzidos e se estes atendem o rigor metodológico exigido em pesquisas dessa natureza. Dentro do escopo dessa pesquisa, o presente trabalho possui um recorte específico, focalizando a avaliação da produção 
científica que se intitula estudos de revisão em Educação veiculada entre 2000 e 2016 em uma das revistas da área: a revista Pro-Posições.

\section{MATERIAL E MÉTODOS OU METODOLOGIA}

Inicialmente, fez-se o levantamento e identificação das produções da revista no período da pesquisa. O periódico encontra-se inteiramente disponível on-line. Nesse processo, a leitura dos resumos foi fundamental para discernir quais textos se adequavam aos estudos, e assim localizou-se quatro artigos. A partir disso, fez-se leitura integral desses textos seguida da elaboração de fichas que destacassem os seguintes aspectos; caracterização dos estudos e categorização de autores e temas abordados, o predomínio de autorias na publicação (se individuais ou grupos); foco de interesse em temáticas, localização geográfica e concentração da produção científica por região. Foi necessário fazer uma avaliação de cada artigo, na íntegra, sem que houvesse muitas categorias ou a necessidade de utilizar gráficos e tabelas. Assim, a análise de cada texto e a perspectiva geral da Pro-posições foi feita sob as abordagens dos estudos de revisão.

\section{RESULTADOS E/OU DISCUSSÃO}

Os quatro artigos encontrados foram "Teses e dissertações sobre gênero e desempenho escolar no Brasil (1993-2007): um estado da arte" escrito por Marilia Pinto Carvalho e publicado no ano de 2012 , "Algumas tendências e perspectivas em artigos publicados de 2009 a 2014 sobre surdez e educação de surdos”, escrito por Heloísa Andreia de Mato Lins em coautoria com Lilian Cristine Ribeiro Nascimento, publicado no ano de 2015, "Gênero, sexualidade e políticas públicas de educação: um diálogo com a produção acadêmica", escrito por Cláudia Vianna, publicado em 2012 e "Avaliação da qualidade de vida em docentes brasileiros: uma revisão sistemática" escrito em coautoria por Tárcia Rita Davoglio, Carla da Conceição Lettnin e Cristina Generali Baldissera, publicado em 2015.

A temática de gênero esteve presente em dois artigos, o que representa $50 \%$ do escopo analisado nesse trabalho. Ambos os textos foram publicados no ano de 2012, obtiveram financiamento do CNPQ e fazem um recorte temporal da década de 1990 até os anos 2000. Enquanto Vianna (2012) discorre acerca do gênero e sua relação com as políticas públicas educacionais no Brasil, Carvalho (2012) faz uma análise mais específica e trata da relação entre gênero e desempenho escolar. São duas autoras do sexo feminino, pesquisando as discussões sobre gênero em um momento cujas pautas feministas estão ganhando cada vez mais destaque na literatura.

De forma geral, o trabalho de Vianna (2012) faz uma análise contextualizada, mas deixa a desejar na sistematização das informações dos artigos, não sendo preciso os dados coletados, Carvalho (2012) faz o oposto, com uma sistematização eficiente, mas uma análise que ainda pode ser aprofundada. Esse aspecto indica a falta de uma metodologia rígida na realização dessas pesquisas, uma vez que há essa flexibilidade do autor em privilegiar determinados aspectos em detrimento de outros. Contudo, ressalto que a sistematização objetiva, precisa e consistente dos resultados é o primeiro passo 
para a construção de um estado da arte, de modo que a própria análise feita posteriormente ficará comprometida caso haja evasão na divulgação dos resultados.

$\mathrm{O}$ terceiro artigo analisado nesse trabalho intitulado "Algumas tendências $e$ perspectivas em artigos publicados de 2009 a 2014 sobre surdez e educação de surdos escrito em coautoria por Heloisa Andreia de Matos Lins e Lilian Cristine Ribeiro Nascimento e publicado no ano de 2015(LINS; NASCIMENTO,2015). Sem nenhuma agência financiando a pesquisa (ao menos sem que conste no artigo), as professoras analisaram 73 artigos publicados em periódicos científicos arbitrados e vinculados ao Scientific Electronic Library Online (SciElo), no período de 2009 a 2014, em âmbito nacional, acerca da surdez e educação de surdos. É um artigo que cumpre os objetivos anunciados e vai além deles ao sistematizar e discutir as principais tendências no campo da educação de surdos. Mesmo utilizando apenas os resumos dos textos selecionados, apresenta uma análise de caráter global sobre as produções e assim possibilita uma aproximação com as tendências dos estudos da educação de surdos e surdez, no período de 2009 a 2014.

O último artigo que o presente trabalho analisa foi escrito por três pesquisadoras, Tárcia Rita Davoglio, Carla da Conceição Lettnin e Cristina Generali Baldissera: "Avaliação da qualidade de vida em docentes brasileiros: uma revisão sistemática". Foi publicado no ano de 2015, estuda doze (12) artigos que se debruçam sobre a qualidade de vida - QV de docentes, selecionados a partir dos critérios dos pesquisadores nas Bases de Dados eletrônicas Scielo, Lilacs e Pepsic, abarcando o período entre 2000 a 30 de abril de 2014. A revisão sistemática é feita com maestria, pois é explicado o conceito de QV, os critérios de seleção dos artigos, a metodologia é detalhada e a análise consegue abarcar todos os pormenores dos textos. Assim, o trabalho se caracteriza como estado da arte, preenchendo todos os requisitos desse tipo de estudo. (DAVOGLIO; LETTNIN; BALDISSERA, 2015)

\section{CONSIDERAÇÕES FINAIS}

Mapear e caracterizar as tendências metodológicas desses trabalhos foi uma experiência conflitante, pois apesar de ser um escopo pequeno de textos, os enfoques metodológicos não seguem uma linearidade, evidenciando a falta de um padrão na produção desses estudos, o que pode ser atribuído a incipiência da realização de estado da arte no Brasil. Além da ausência de rigidez metodológica, outra característica que chama a atenção é a multiplicidade de nomenclaturas, marcada pelo pouco uso do termo 'estado da arte' ou 'estudo de revisão' bem como o uso dessas palavras em estudos que se caracterizam como levantamentos bibliográficos mais simples.

A publicação desses textos foi nos anos finais do recorte temporal deste estudo, o que denota o caráter principiante do periódico em relação à produção de estudos de revisão. Em relação às temáticas, é pertinente apontar que todos os textos buscam analisar pesquisas que estudem sujeitos desprestigiados socialmente: mulheres, surdos e professores. Assim, como mostra Certeau (2011) ao dizer que todo discurso está inserido em um lugar de produção socioeconômico, político e cultural, o lugar social de onde parte esses textos flertam com o movimento de autocrítica das produções 
universitárias, e de forma mais ampla tenta entender como a Ciência faz uso de seu espaço, ao investigar grupos desfavorecidos pelo machismo, patriarcalismo e homofobia, no caso das pesquisas com a temática de gênero, do preconceito advindo de uma sociedade majoritariamente ouvinte, no caso da comunidade surda e da desvalorização da educação cujos docentes são atingidos.

Além do mapeamento da revista, o presente trabalho também ratifica a relevância do estado da arte para ampliar os estudos e pesquisas em temas lacunares na produção acadêmica e sintetizar o que já foi escrito. Assim, é fundamental que haja uma familiarização com a metodologia desse tipo de estudo, a fim de refinar as futuras pesquisas não só para a área da educação mas para todos os âmbitos do conhecimento.

\section{REFERÊNCIAS}

CARVALHO, Marília Pinto. Teses e dissertações sobre gênero e desempenho escolar no Brasil (1993-2007): um estado da arte. Pro-Posições, v. 23, n. 1, p. 147-161, jan./abr. 2012.

CERTEAU, Michel de. A Escrita da História. $3^{\text {a }}$ ed. Rio de Janeiro: Forense Universitária, 2011.

DAVOGLIO, Tárcia Rita; LETTNIN, Carla da Conceição; BALDISSERA, Cristina Generali. Avaliação da qualidade de vida em docentes brasileiros: uma revisão sistemática. Pro-Posições, v. 26, n. 3, p. 145-166, set./dez. 2015.

LINS, Heloisa Andreia de Matos; NASCIMENTO, Lilian Cristine Ribeiro. Algumas tendências e perspectivas em artigos publicados de 2009 a 2014 sobre surdez e educação de surdos. Revista Pro-Posiçõoes, v. 26, n. 3 (78), p. 27-40, set./dez. 2015.

ROMANOWSKI, Joana Paulin; ENS, Romilda Teodora. As pesquisas denominadas do tipo "estado da arte" em educação. Revista diálogo educacional, v. 6, n. 19, p. 37-50, set./dez. 2006.

VIANNA, Cláudia. Gênero, sexualidade e políticas públicas de educação: um diálogo com a produção acadêmica. Pro-Posições, v. 23, n. 2, p. 127-143, mai./ago. 2012. 